\title{
Principals, Trust, and Cultivating Vibrant Schools
}

Megan Tschannen-Moran

College of William and Mary

Christopher R. Gareis

College of William and Mary

Follow this and additional works at: https://scholarworks.wm.edu/educationpubs

\section{Recommended Citation}

Tschannen-Moran, M., \& Gareis, C. (2015). Principals, trust, and cultivating vibrant schools. Societies, 5(2), 256-276.

This Article is brought to you for free and open access by the School of Education at W\&M ScholarWorks. It has been accepted for inclusion in School of Education Articles by an authorized administrator of W\&M ScholarWorks. For more information, please contact scholarworks@wm.edu. 
Article

\title{
Principals, Trust, and Cultivating Vibrant Schools
}

\section{Megan Tschannen-Moran * and Christopher R. Gareis}

Educational Policy, Planning, and Leadership, College of William \& Mary, P.O. Box 8795, Williamsburg, VA 23187-8795, USA; E-Mail: crgare@wm.edu

* Author to whom correspondence should be addressed; E-Mail: mxtsch@wm.edu; Tel.: +1-757-221-2187; Fax: +1-757-221-2988.

Academic Editors: Kenneth Leithwood and Jingping Sun

Received: 17 February 2015 / Accepted: 17 March 2015 / Published: 27 March 2015

\begin{abstract}
Although principals are ultimately held accountable to student learning in their buildings, the most consistent research results have suggested that their impact on student achievement is largely indirect. Leithwood, Patten, and Jantzi proposed four paths through which this indirect influence would flow, and the purpose of this special issue is to examine in greater depth these mediating variables. Among mediating variables, we assert that trust is key. In this paper, we explore the evidence that points to the role that faculty trust in the principal plays in student learning and how principals can cultivate trust by attending to the five facets of trust, as well as the correlates of trust that mediate student learning, including academic press, collective teacher efficacy, and teacher professionalism. We argue that trust plays a role in each of the four paths identified by Leithwood, Patten, and Jantzi. Finally, we explore possible new directions for future research.
\end{abstract}

Keywords: trust; principal; indirect effects; mediating variables; student achievement; academic press; collective teacher efficacy; teacher professionalism

\section{Introduction}

Principals are charged with providing hands-on leadership to one of the most significant institutions in our society, the schoolhouse. Our society is well served when schools function at their highest level. Students develop the skills, values, and habits of mind that will allow them to become productive and engaged citizens of our democracy. The well-being of our society suffers when schools fail to 
adequately fulfill our hopes for them, when the learning of both students and faculty alike are impaired by a lack of safety, low morale, or unresolved conflict,. There are a myriad of responsibilities placed on the shoulders of principals in order to foster the kinds of learning environments we hope for. A growing body of research suggests that primary among these is earning the trust of their teachers and exercising the requisite skills to cultivate a pervasive culture of trust between teachers and students [1].

Trust is increasingly recognized as an essential element in vibrant, well-performing schools. This is, in part, because trust undergirds the cooperative behavior necessary for cultivating high performance. Trust becomes salient when people enter into relationships of interdependence, where the outcomes one desires cannot be met without the involvement and contribution of others. Once trust is established, the confidence one holds in the intentions and capacity of the other person to fulfill one's expectations results in feeling a greater sense of ease in the interdependence and a willingness to take risks. Trust also is a dynamic construct in that it can change over the course of a relationship, as the nature of the interdependence between two people changes, and as expectations are either fulfilled or disappointed. Although trust occurs between individuals, it also occurs among individuals within complex human organizations, such as schools. Without trust, organizational effectiveness and efficiency are hampered [2-4].

Trust is a multifaceted construct, meaning that people assess many elements simultaneously when making judgments of trust. These elements, or facets, may vary somewhat depending on the context or nature of the trust relationship. Specifically, trust is defined as the willingness to be vulnerable to another party based on the confidence that the other party is benevolent, honest, open, reliable, and competent $[3,5]$. Although most educators acknowledge the importance of trust in their work, these qualities too often get squeezed out with the pressures of accountability. Such pressures can drive school leaders to impatience and anxiety, resulting in a climate of tension and fear that interferes with the learning of both children and adults alike. These schools are likely to be dreary and discouraging places rather than the joyful learning communities we long for. Cultivating a climate of trust, in contrast, allows the members of a school community to amplify their school's strengths and create environments where curiosity and love of learning abide. Student learning is facilitated by equipping school leaders and teacher leaders to more fully realize their positive intentions for their professional relationships resulting in strong relationships of trust. In so doing, the learning of teachers and students is enhanced.

A school principal is charged with a wide array of responsibilities, including the development of a shared vision for the school and stewardship of that vision, fostering an environment conducive to student learning, engaging all members of the school community, managing the organization, ensuring the effectiveness of the faculty, and doing these things with integrity and fairness [6]. In enacting these various duties, they have both a direct and an indirect influence on student learning [7,8]. Although principals are ultimately held accountable to student learning in their buildings, the most consistent research results have suggested that their impact on student achievement is largely indirect $[1,7,9]$. The purpose of this special issue is to examine the mediating variables through which those indirect effects function, and among those variables trust is certainly among the strongest. In this paper, we will explore the evidence that points to the role that faculty trust in the principal plays in student learning, how principals can cultivate trust by attending to the five facets of trust, as well as the correlates of trust that mediate student learning. 


\section{Trust and Student Achievement}

School leaders who create bonds of trust help create the conditions that inspire teachers to move to higher levels of effort and achievement [9-16]. In contrast, when teachers and principals do not trust one another, each seeks to minimize their vulnerability and risk by adopting self-protective stances. The result can be disengagement that consequently diminishes student learning [2]. Few other variables examined by educational researchers come close to the level of predictive power of trust on student achievement.

Because of the nature of interdependence between teachers and principals, and the authority that principals exercise in relations to them, teachers tend to pay particular attention to the trustworthiness of their principals. In a study that included elementary, middle, and high school levels in both urban and suburban settings, Tschannen-Moran [17] found that the level of trust teachers held for the principal set a tone for the building. Faculty trust in the principal was related to their trust in colleagues, students and parents, as well as the level of parent trust in the school. Student trust in teachers was not directly related to faculty trust in the principal; however, it was indirectly related to the overall climate of trust in the schools through intercorrelations with the remaining faculty and parent trust measures. Each of these five types of trusting relationships in schools was moderately to strongly related to student achievement. Moreover, $78 \%$ of the variance in student achievement was explained by the combined influence of these five trust variables. This is powerful evidence that trust is an essential element of productive schools. The correlations between faculty trust in principal and faculty trust in colleagues speaks to a tone set by administrators that influences the climate of the school [16]. Where the principal has established high trust relationships, teachers are more likely to perceive that they can trust their colleagues as well. Conversely, where trust in the administrator is low, trust in colleagues is likely to suffer as well. In schools where principals, teachers, students, and parents trust each other, a climate of success is more likely. These schools are better positioned to accomplish the essential educational goals of fostering student achievement and equipping students for citizenship. It is interesting and important that both faculty trust in the principal and trust in colleagues are related to faculty trust in students [17]. Where the adults trust one another, they are more likely to extend trust to their students as well. In contrast, where distrust characterizes the relationships among the adults in a school, the trust between teachers and students is likely to suffer as well.

In a related study, Tschannen-Moran and Gareis [1] found both a direct relationship between principal trustworthiness and student achievement, as well as evidence of an indirect influence of this trustworthiness on student achievement through elements of school climate, including teacher professionalism, academic press, and community engagement. This suggests that when principals are trustworthy, they set a tone that influences how teachers relate to one another, to students, and to the community at large. These, in turn, were individually and collectively related to student achievement [1]. The findings of this study reflect both current and evolving conceptions of school leadership, which explicitly include the fostering and use of trust as a professional responsibility of school leaders $[6,18]$. We explore below the principal behaviors that cultivate trust as well as three correlates of trust in schools. 


\subsection{Vulnerability}

Trust is most relevant when two or more parties are dependent on one another for something they need or care about. The goals that educators aspire to are far beyond what any individual alone can accomplish. Therefore, educators are necessarily interdependent, and with interdependence comes vulnerability. Trust is characterized by the extent to which one is willing to rely upon and make oneself vulnerable to another and to do so with a certain sense of ease or comfort [19,20]. The uncertainty concerning whether the other intends to and will act appropriately, however, entails taking a risk [21,22]. The person extending trust recognizes the potential for betrayal and harm from the other. Taking that leap of faith requires trust. This leap may, in turn, create the conditions for the development of even deeper trust when the expected behavior becomes manifest.

Trust has been defined as a willingness to make oneself vulnerable to someone else in the belief that your interests or something that you care about will not be harmed [3]. For a school leader, this can mean being trustworthy to others in the sense of acknowledging, allowing, and protecting others' demonstrations of vulnerability toward her- or himself. It can also mean extending trust by demonstrating some degree of vulnerability to others. In either case, the facets of benevolence, honesty, openness, competence, and reliability constitute the behaviors that potentially foster trust among principals, teachers, students, and others in school communities.

\subsection{Benevolence}

A starting point for the development of trust is a sense of caring or benevolence. For principals to earn the trust of their teachers, they must demonstrate genuine care for teachers, students, and parents alike. Benevolence is characterized by a generalized spirit of good will and a willingness to extend oneself in support of the well-being of the other. School leaders can promote trust through exhibiting benevolent behaviors, such as showing consideration and sensitivity for employees' needs and interests, acting in a way that protects employees' rights, and refraining from exploiting others for personal gain. This creates the confidence in teachers that their well-being or something they care about will be protected and not harmed by the person they have trusted [19,23].

Trust rests on the assurance that one can count on the good will of another person to act in one's best interest and to refrain from knowingly or willingly doing one harm. In an ongoing relationship, the future actions or deeds required for continued trust are typically not specified; there is simply the assumption of an attitude of mutual good will [24]. The sense of care for the person and the relationship are so strong that one can rest assured that the other person would not capitalize on an opportunity to enhance their outcomes and willingly forego personal gain if it would bring potential harm to the trusting party if such an opportunity were to come at the expense of the trusting partner [25]. Principals who hope to earn the trust of their faculties need to demonstrate good will and genuine concern for teachers' well-being.

Akin to benevolence is respect or the recognition of the inherent worth or value of another person and the contributions they make to the collective. In a situation in which one is dependent upon and consequently vulnerable to another, faith in the caring intentions or altruism of the other is particularly important. Teachers want to feel assured that they will be treated fairly and with respect. This aspect of 
a perception of benevolence suggests an affective or emotional element to trust. Indeed, Leithwood, Patten, and Jantzi [7] classify trust as one factor in a construct labeled the Emotions Path of School Leadership. However, the perception of benevolence also involves cognitive judgment of the behaviors of others and one's experiences with them. Although there is an emotional element to trust, it is not primarily an emotional process. There is an important distinction between trust and affection. For example, it is possible to like someone you do not trust, as well as to trust someone you do not especially like [26]. The perception of benevolence, therefore, is oftentimes anchored in judgments of the behaviors of principals in the daily enterprise of leading and managing the school.

\subsection{Honesty}

Honesty is a fundamental facet of trust [25,27-29]. To be trusted, principals must also be honest in their interactions with teachers [5]. Honest behavior is anchored in moral principles and is cultivated through behaviors that demonstrate integrity of character, authenticity, and accountability for one's actions. When teachers begin to perceive a discrepancy between their principal's words and actions, suspicion is the likely result. The revelation of dishonest behavior may be more damaging to trust than lapses in other facets because it is read as an indictment of the person's character. Once a principal has been caught in a lie and the faculty has lost faith in the word of their principal, it will be hard for them to earn or regain trust because language is an essential tool leaders must use to lead and inspire people.

Honesty entails not only to the conventional sense of telling the truth, but it also includes a sense of integrity and authenticity of behavior [5,28,30-32]. Correspondence between a person's statements and deeds characterizes integrity. Integrity is the perceived match between a person's values as expressed in words and those expressed through action [33]. People earn a reputation of integrity from telling the truth and keeping promises [34]. When a person says one thing yet does another, trust is compromised. Without the confidence that a person's words can be relied upon and can accurately predict future actions, trust is unlikely to develop. Trust might survive a broken promise if a plausible explanation is given along with an apology; however, a pattern of broken promises will likely provoke a serious threat to trust. A sense of fairness and fair play is an essential element of integrity, refraining from using one's authority to play favorites or to improve one's personal outcomes. In this sense, integrity speaks not only to the alignment between the principal's words and deeds but also to living according to a set of core values or principles.

Authenticity has to do with a willingness to be oneself - to truthfully represent one's beliefs and feelings, as well as owning up to one's foibles. Principals who come across as too guarded in what they are willing to reveal about themselves can be perceived as though they have something to hide or are simply playing a role and thus their motivations may be regarded with suspicion. Authenticity also involves a willingness to take responsibility for one's mistakes and avoidance of distorting the truth in order to shift blame to another. There is no passing the buck, no scapegoating, no pointing fingers at others. This means the willingness to accept responsibility not just for good things that happen, but for mistakes and negative outcomes as well. Rather than protecting his or her reputation as hoped, a principal who continually tries to cover his or her own shortcomings and mistakes by shifting blame to others will more likely earn the distrust of both teachers and superiors. Authenticity also means refraining from using one's authority to manipulate subordinates. Authentic leaders treat others as 
people, to be respected as persons rather than as pawns to be manipulated. In addition, authentic leaders are able to break through the barriers of role stereotyping and behave in ways that are consistent with their true self. Their basic personality is a prime motivator of behavior, not their idea of how to play some prescribed role. The perceived authenticity of the principal has been correlated to faculty trust in the principal $[31,32]$.

\subsection{Openness}

Principals win the trust of their faculty through their willingness to extend trust, which is evident through openness with information, influence over organizational decisions, and professional discretion [24]. Teachers see principals as trustworthy when their communication is both accurate and forthcoming $[2,12]$. Principals can foster the open flow of information coming to them by being open with communication that flows from them [2]. When principals exchange thoughts and ideas freely with teachers, it not only enhances perceptions of trustworthiness but leads to greater openness on the part of teachers as well. Adequate explanations and timely feedback on decisions contribute to higher trust [35]. Some leaders withhold important information as a way to maintain power or manipulate employees [36,37]. However, when principals withhold information from teachers, it evokes suspicion as teachers wonder what is being hidden and why. In schools with a greater level of trust, teachers and other staff members are more willing to disclose accurate, relevant, and complete information about problems, as well as to share their thoughts, feelings or ideas for possible solutions, making these valuable resources available for school improvement [23,27,37]. Problems can be disclosed, diagnosed, and corrected before they are compounded.

Openness in influence comes about as leaders recognize that their teachers possess valuable professional knowledge and decentralize decision-making to harness the collective wisdom of teachers $[11,38,39]$. By creating decision-making structures and inviting not just teachers' involvement but influence over organizational decisions that affect them, principals can create the conditions necessary to foster mutual trust $[12,40,41]$. This is particularly the case when the professional expertise of teachers is fundamental to the issue at hand, such as decisions related to instruction or a commitment to student learning and well-being [2,16]. There are two primary reasons for including subordinates in decision making. The first and most common is that it can foster and strengthen teacher compliance with an initiative. The second is the belief that the involvement of teachers will result in higher quality decisions because they have valuable information and insights to share [42]. Teachers who reported substantial influence and autonomy in their work environments have been found to hold higher trust in their principals $[43,44]$. Thus, an authentic professional learning community can potentially be a facilitating element of a school's student achievement [45].

Closely related to the sharing of influence over decision-making and problem-solving is the principal's willingness to grant discretion to teachers. Discretion is rooted in a confidence in teachers' reliability and competence (which are two facets of trust) and a willingness to delegate important tasks to them. Delegating decision authority to teachers in instructional decisions that rely on teacher expertise and commitment to students not only fosters trust, it also promotes greater professionalism because discretion that is at the very heart of professional practice [2,16,46,47]. Using good judgment in this context means considering the maturity and commitment of those with whom you would share 
information and influence, and working overtime to build capacity if it is lacking initially. Through the exercise of behaviors associated with democratic leadership, principals can achieve the goals of the organization, thus both engendering and making use of trust $[6,18]$.

A leadership style in which the principal is perceived to be approachable and open to the ideas of teachers, who is willing to accept questions and acknowledge that divergent opinions exist and who seeks to put into practice suggestions from the faculty has been linked to greater faculty trust in the principal $[1,5,12]$. Such an open leadership style has been associated with increased motivation and commitment to shared goals as well as improved school performance [48]. A professional orientation on the part of principals has been found to engender greater trust from their teachers, to predict greater instructional capacity among a school's faculty, and to produce greater achievement among the school's students $[11,16]$. Moreover, a large-scale study of principals' leadership was found to impact school performance more by strengthening teachers' professional community than by directly influencing their instructional practices [49].

\subsection{Competence}

Competence is the ability to perform a task as expected, according to appropriate standards. In schools, principals and teachers depend upon one another's competence to accomplish the teaching and learning goals of the school. When principals demonstrate the ability to get the job done, whatever that job may entail, teachers are more inclined to trust in the principal. Teachers depend upon the principal to manage the complex tasks inherent in this role successfully in order to fulfill the similarly complex responsibilities they have in teaching young people. Leithwood, Patten, and Jantzi [7] classify such tasks as associated with the Rational Path and the Organizational Path of school leadership, through which a principal demonstrates essential knowledge of and skills associated with "curriculum, teaching, and learning" [7] (p. 673) and with the "structures, cultures, policies, and standard operating procedures" [7] (p. 678) of the school. More specifically, Leithwood and his colleagues identify academic press, disciplinary climate, and protecting instructional time as key examples of classroom and school variables that may mediate student achievement. Notably, faculty trust in the principal relies heavily on the competence of principals relative to their various responsibilities as school leaders [12]. Therefore, trustworthy principals adopt knowledge, skills, work habits, and systems that enable them to achieve the myriad tasks necessary to operate and lead a school $[12,39,50]$.

Teachers often mention incidents in which the competence of their principal matters. In a study of three high-trust and three low-trust schools, competence was the most often mentioned element contributing to the trust or distrust of the school leader [12]. Skills related to competence included setting high standards, pressing for results, solving problems, resolving conflicts, working hard, and setting an example. In high-trust schools, principals are regarded with respect and even admiration. In these schools, the principals not only set a high standard, they also hold teachers accountable in ways that seem fair and reasonable to their staff.

Principals are tasked with influencing student performance by shaping the school's learning-focused mission and aligning the school's structures and culture to serve the mission [51]. They accomplish this by focusing on the core tasks of schooling including choosing appropriate curriculum, improving instruction, managing school context, and improving student learning [52,53]. The principal 
must engage with teachers regularly and effectively in order to effect change in their instructional practices [54-56]. Principals' leadership involves impacting practices both through faculty-wide efforts and through individualized efforts, each of which represent important means to improve instruction and, therefore, student performance [57]. Thus, competence in school leadership can take the form of teacher professional development, curriculum development, and teacher supervision [12,58]. Other forms of competence in school leadership include the use of data in discussions about practice, monitoring teachers' lesson plans, and focusing a school community on its collective responsibility for educational excellence through partnerships and community development [54].

The primary responsibility of principal leadership is to improve student learning outcomes by strengthening teachers' instructional practices [56,59-61]. Though research suggests the effect of principal leadership on student achievement may be indirect, it is nonetheless significant, especially in relationship to teachers' instructional performance [7,8,49,62-65]. In a meta-analysis of 27 research studies, Robinson et al. [56] found significant links between leadership and student outcomes. They noted that leadership competence in promoting teacher learning and development was most strongly predictive of positive student outcomes, but that relationship-developing strategies were woven throughout all aspects of school leadership.

\subsection{Reliability}

The fostering and sustaining of trust also involve reliability. Reliability means following through on decisions and promises. It entails a sense of confidence that one can rest assured that another person (e.g., the principal) can be counted on to do what is expected on a regular, consistent basis. Reliability combines a sense of predictability with elements of benevolence and competence. In a situation of interdependence, when something is required from another person or group that impacts joint outcomes, partners can consistently be relied upon to supply it [27,37]. When principals demonstrate enough consistency in their behavior to inspire confidence that teachers can count on them in their time of need, teachers need not invest energy worrying whether the principal will come through in a difficult situation. Neither will they expend energy making mental provisions of how they will manage in case the principal fails to come through.

It is an accepted truism that the best predictor of future behavior is past behavior. Thus, principals who reliably act in ways that elicit trust across time and settings are more likely to earn and maintain the trust of their faculty than those who do not [1-3]. Teachers want to be able to depend upon the actions of their principal, and teachers tend to have greater confidence in their own decision-making and actions when they feel they can predict the behavior of their principal [12]. Teachers may conclude that their principal means well, and even that he or she is very capable and helpful if you can get his or her attention. However, if trouble managing the time demands of the job, being easily distracted, or lapsing in decision-making means teachers cannot count on the principal to come through for them when needed, the teachers are unlikely to extent trust in the relationship. In a sense, the facet of reliability must be present in each of the other four facets of trust such that a principal's behaviors associated with benevolence, honesty, openness, and competence are consistent. 


\subsection{Trustworthy Leadership}

Principals hold authority and responsibility for student achievement and other important educational outcomes of schooling, although their effect tends to be indirect and largely dependent upon the effectiveness of teachers. Principles work with and through teachers to pursue the educational mission of their schools; therefore, the relationship between the principals and their teachers must be one that facilitates the myriad judgments, decisions, and actions that occur within schools. Trust has been found to be associated with the qualitative nature of professional relationships and the outcomes of those relationships in terms of practice and student achievement. Interrelationships and behaviors characterized by benevolence, honestly, openness, competence, and reliability can cultivate trust between principals and teachers, and the presence of genuine trust can thereby mediate other correlates associated with student learning.

\section{Correlates of Trust in Schools}

Intuitively and empirically, trust is a powerful construct when considering influence on and through behavior in the pursuit of the educational mission of schools. Yet, trust does not operate irrespective of other important constructs. As Leithwood, Patten, and Jantzi [7] assert, there are undoubtedly numerable mediators that must exist between leadership actions and the experiences of and outcomes for students. Here we briefly explore three such mediators, each explicitly or implicitly addressed by Leithwood and his colleagues' investigation of four Paths of Leadership. However, we contend that these three mediators, as correlates of trust, are indicative of the centrally important role that trust plays in how leadership influences student learning. Specifically, we turn our attention to the relationship of trust to academic press, collective teacher efficacy, and teacher professionalism.

\subsection{Academic Press}

Growing out of research on effective schools more than three decades ago, the construct of academic press has persistently been identified as a variable in student achievement [7]. Murphy et al. [66] described academic press as "the degree to which environmental forces press for student achievement on a schoolwide basis" [66] (p. 22) and that academic press "pulls together various forces-school policies, practices, expectations, norms, and rewards - generated by both staff and students" [66] (p. 22). The inclusion of "norms" in this definition is particularly relevant, as academic press may be leveraged by school policies and practices, but it is also dependent upon norms of behavior that exist among members of a school community. Goodard, Sweetland, and Hoy [67] explained that academic press can be characterized as a normative environment where teachers both believe that students are capable of succeeding academically and they press to help struggling students meet academic expectations. Such schools are places where teachers set high academic expectations, create a learning environment that is orderly and serious, and make an extra effort to assist students to learn. In these schools, not only do teachers and administrators have high expectations of students, but students work hard, and they respect other students who are academically motivated $[68,69]$.

Research on academic press indicates a strong link between the construct and student achievement [67-74]. Leithwood et al. [7] characterized academic press as a factor in the Rational 
Path of School Leadership. Indeed, academic press is elemental to instructional leadership, which is a core strand of professional responsibility for educational leaders [6,18]. The second standard of the current school leadership standards, referred to as the instructional leadership standard [75], states that "an educational leader promotes the success of every student by advocating, nurturing, and sustaining a school culture and instructional program conducive to student learning and staff professional growth" [6] (p. 14). Core functions or roles related to instructional leadership include creating a rigorous curriculum and a motivating learning environment, which are conceptually related to the construct of academic press. The responsibility of the school leader is also to cultivate norms of behaviors among members of the school community that are conducive to student achievement. We contend that behaviors that demonstrate benevolence, honesty, openness, competence, and reliability—all facets of trust — are inherent to such a school culture.

The relationship among instructional leadership, academic press, and trust is important to explore, as Leithwood, Patten, and Jantiz [7] contend, "enough evidence is now at hand to justify claims about significant leadership effects on students that the focus of attention for many leadership researchers has moved to include questions about how those effects occur" [7] (p. 672). In this vein, Mitchell, Kensler, and Tschannen-Moran [76] found that instructional leadership has a significant direct effect on school academic press. Instructional leadership was also positively correlated with academic achievement in bivariate correlations and had an indirect effect on academic achievement in a structural equation model, even when controlling for the effects of SES and school level. Although research on academic press has typically relied only on the perceptions of teachers, Mitchell et al. [76] found a convergence in the perceptions of academic press among teachers, students and parents in a school. As in prior studies that have examined the relationship between academic press and student achievement [67-74], they found academic press to be strongly correlated with and predictive of achievement aggregated to the school level. In fact, school academic press had the largest direct effect on student achievement over and above the negative effects of low SES. Strong evidence exists for the importance of creating a school culture that is characterized by academic press in order to foster student achievement.

Within the instructional leadership standard, the first function or role of the educational leader is to "nurture and sustain a culture of collaboration, trust, learning, and high expectations" [6] (p. 14). In this standard, both academic press (high expectations) and trust are alluded to, thus conceptually suggesting the important interrelationships that exist between the constructs. Indeed, our recent research into this relationship suggests that the level of academic press in a school is related to principal trustworthiness [1]. When a principal is able to cultivate a learning environment that is serious in purpose (that is, focused on student achievement) and orderly, including setting expectations for the behavior of students and staff, then student achievement is likely to be higher. Such findings suggest the reciprocal influences that leadership behaviors have in the cultivation of the norms of a school that ultimately create the rich educational environment (i.e., the school culture) in which student motivation, effort, and achievement take root.

\subsection{Collective Teacher Efficacy}

Collective teacher efficacy is a motivational construct based on the shared perceptions of teachers in a school that the efforts of the faculty as a whole will have positive effects on students. These beliefs 
can powerfully shape group behavior and group outcomes through the goals, effort, perseverance and resilience that flow from them [77-79]. Teachers are more likely to persist in efforts toward goals that they believe they can accomplish. These shared beliefs become manifest in the norms of a school and the casual conversations among teachers concerning expectations about the likelihood of success of a school faculty. Teachers' collective sense of efficacy has been linked to student achievement, even when taking into account the socioeconomic status of students [77,80,81].

Principals can help to cultivate and nourish strong collective efficacy beliefs through communicating confidence in the ability of teachers to promote student learning, whatever the difficulties and challenges of the particular context of the school. Principal leadership has been found to influence teachers' beliefs that they could make a positive difference in student performance, which in turn resulted in stronger efforts and improved outcomes [60].

When a high level of trust prevails in a school, a sense of collective efficacy tends to be evident as well. This collective sense of being able to successfully fulfill the central mission of the school has been linked to teachers' trust in one another as well as to teachers' trust in students and parents [82]. When a school is characterized by high trust, it is more likely that they will develop greater confidence in their collective ability to be successful at meeting their goals [79]. A virtuous cycle in which trust, success, and collective efficacy reinforce one another can be set in motion. Thus, in a study of urban elementary schools, Tschannen-Moran [3] found that trust bolstered the risk taking of experimenting with new teaching practice, which was rewarded with higher student achievement, and which in turn raised the collective sense among teachers that they could make a difference even among their most disadvantaged students. In their exploration of four "paths" of school leadership that influence student learning, Leithwood, Patten, and Jantzi [7] observed that "evidence points to considerable interaction among Paths". Within their investigation of the paths, the constructs of collective teacher efficacy is posited as one of two key indicators of the Emotions Path. The other construct associated with the Emotions Path is trust. While distinct as constructs, the interrelationship between collective teacher efficacy and trust seems evident in fostering the organizational conditions critical to student achievement.

\subsection{Teacher Professionalism}

To meet the changing expectations and challenging new standards demanded by a shifting global economy and new technologies, teachers' professionalism has never been more important. Professionalism requires a commitment to the needs of clients; skillful use of assessments, and the capacity to develop individualized interventions based on the needs of clients. It also entails abiding by a set of norms, standards, and ethics established by the profession, and engaging in ongoing, disciplined, professional inquiry into the best available knowledge [16]. In schools where teacher professionalism is high, teachers perceived their colleagues to be committed to students - competent, cooperative, and supportive. Where professionalism is low, teachers question the professional judgment of their colleagues.

In their study of the four Emotions Paths of School Leadership that influence student achievement, Leithwood, Patten, and Jantzi [7] do not refer explicitly to teacher professionalism; however, the construct of professional learning communities (PLCs) is included as one of two potential factors of 
the Organizational Path. In their review of research, Leithwood et al. state "student learning improved when teachers participated in PLCs," and leadership behaviors that facilitate the creation and effectiveness of PLCs are described as "supportive," "professional," and "protecting" [7] (p. 680). While not synonyms of trust, the normative, interrelational, and ethical language of PLCs is suggestive of facets of trust, such as benevolence, competence, honesty, openness, and reliability.

Teachers who trust their principal are more likely to be open about both their successes and challenges in the classroom, whereas teachers who distrust their principal will be guarded and more likely to engage in self-protective behaviors that may impair the sense of professional community in a school [17]. Moreover, faculty trust in principals has been linked to faculty perceptions of the professional orientation of a principal, suggesting that principals set the tone of professionalism in their buildings [16]. School leaders with a professional orientation do not abuse their power to enforce policies through the overuse of punishments, but neither do they abdicate their responsibility for leadership [39,50]. They engage in coaching and collaboration to bring underperforming teachers into alignment with professional standards, as well as to provide resources to continually extend the professional knowledge of all teachers in their building [3].

In order to support teachers in their development as professionals and as they are asked to change their fundamental beliefs and instructional techniques, they are asked to forge professional communities in their schools and disciplines. These professional communities function best when they are anchored in trust and teamwork $[83,84]$. A school-wide culture of trust, and especially trust in the principal, has been found to be an important precondition for the development of professional learning communities $[85,86]$. Trustworthy behavior on the part of the principal has been related to teachers' perceptions of the professionalism of their colleagues $[1,16]$. That is, where teachers felt that they could put their faith in the principal and that their principal was someone to whom they could turn for assistance with instructional matters, they rated the professionalism of their colleagues more positively. Conversely, where teachers did not trust their principals, they were also likely to regard their colleagues as not exercising professional judgment and competence. Predictably, enthusiasm for teaching was also lower when trust in the principal was lower. Thus, the relationship between faculty trust in the principal and teacher professionalism is likely one of the mechanisms at play in the indirect link between trust in the principal and student achievement.

\subsection{Trustworthy Leadership and Correlates of Trust}

Trustworthy leadership on the part of the principal has been shown to be related to three powerful aspects of school culture: academic press, collective teacher efficacy, and teacher professionalism. What's more, these three correlates are themselves strongly related to one another. Where teachers conduct themselves with a higher degree of professionalism, there is likely to be greater seriousness and celebration of the academic mission of the school and a stronger shared belief among the faculty of their capacity to make a difference. By way of contrast, where any one aspect of the school culture begins to suffer, they are all likely to decline as well. Trust, then, is an important factor associated with student achievement, as well as an important mediator of other leadership behaviors associated with student achievement. 


\section{Implications}

In their exploration of school leadership influences on student achievement, Leithwood, Patten, and Jantzi [7] provide "an initial and partial test of a new conception, metaphorical in nature, of how leadership influences student learning" [7] (p. 673). The metaphor is of "four distinct 'Paths' along which leadership influence flows to improve student learning" [7] (p. 673). This includes the Rational Path, Emotions Path, Organizational Path, and Family Path. The metaphor is apt, as paths simultaneously suggest both a means and intended outcome. In exploring the implications of trust as a mediating variable of school leadership and student achievement, we offer another metaphor, that of cultivation.

Metaphorically, trust may have a cultivatory role in school leadership. To cultivate means to prepare and use land for raising crops. In a similar way, trust can have dual functions of both preparing a school culture for student achievement and using it as an elemental resource in the complex and continuing acts of teaching and learning. To extend the metaphor, trust may not be the seed of student achievement, but it may well be the rich soil in which the seeds of effective teaching and learning can take root and grow. The organic metaphor appeals to us, in part, because the acts of teaching and learning are inherent to human behavior and thus are grounded in human interactions.

More practically speaking, trust may not be only a factor associated with one path of school leadership, such as the Emotions Path posited by Leithwood et al. [7]. Rather, there is evidence that trust may be a mediating variable for other factors associated with student achievement, such as academic press, collective teacher efficacy, and teacher professionalism. This conceptualization is evident in the proposed revised standards for educational leadership [18], which include a number of references to the role of leaders in cultivating trust and a culture of values, attitudes, and, importantly, behaviors that focus on student learning. The standards are clear that creating, maintaining, and sustaining such a culture (that is, cultivating such values and behaviors) is the responsibility of the educational leader. Indeed, note the repeated references to elements of leadership, school culture, and trust in two of the new standards:

Standard 5: An educational leader promotes the success and well-being of every student by promoting the development of an inclusive school climate characterized by supportive relationships and a personalized culture of care [18] (p. 18).

This standard includes such leadership functions as the following:

- Ensures the formation of a culture defined by trust

- Ensures that each student is known, valued, and respected

- Ensures that students are enmeshed in a safe, secure, emotionally protective, and healthy environment [18] (p. 18).

Similarly, there is such language in the new Standard 6:

Standard 6: "An educational leader promotes the success and well-being of every student by promoting professionally normed communities for teachers and other professional staff." [18] (p. 18). 
Standard 6 includes leadership functions such as:

- Ensures the formation of a culture defined by trust

- Fosters and supports the growth of trust [18] (p. 18).

The principal has significant influence on the culture of a school, and the culture of a school is oftentimes reflected in the principal's values, attitudes, and behaviors. Inherent to a school culture that fosters student achievement is trust. In schools that enjoy a culture of trust, staff and students tend to have a shared focus on and expectation of student learning; teachers tend to have a shared sense that they can make a difference in students' lives; and they tend to respect one another, share expertise, and learn from one another. If schools are to reap the rewards of a trusting work environment, it is the principal's responsibility to build and sustain trusting relationships [87].

Trustworthy leadership is cultivated over time, through repeated interactions in which behaviors associated with benevolence, honesty, openness, competence, and reliability are enacted. Indeed, by definition of the facet of reliability, trust must be maintained, once established, through repeated and consistent behavior of the school leader. The leader's own decisions and behaviors are a primary means by which the norms of a school - its culture, the group's way of interacting and behaving - are cultivated and then used as a facilitating means of bringing about student well-being and achievement. In other words, trust within schools must be nurtured by school leaders not only for the inherent worth of trust but because trust plays a mediating role on other important elements of school culture and leadership that are related to student achievement [1].

Leithwood, Patten, and Jantzi [7] argued that identifying "powerful leadership mediators" is important because school leaders "are in the business of deciding where best to focus their efforts" [7] (p. 673). While Leithwood and his colleagues posit that trust may be one factor related to the Emotions Path of School Leadership, we would suggest that trust may in fact mediate a number of factors related to student achievement. If this is the case, then the implications for educational leadership preparation, induction and mentoring of novice school leaders, and the supervision and evaluation of educational leaders become quite important. For example, understanding and developing the dispositions and skills associated with trustworthiness in a complex, public position such as that of a school principal would be necessary for novice and experienced school leaders alike. Closely related - and perhaps even foremost - would be the need to further refine our understanding of the construct of trust and to further investigate its relationship to other factors of schools related to student achievement.

\section{Directions for Future Research}

Leithwood, Patten, and Jantzi conclude their article with a call for educational leadership research to "focus on discovering the leadership practices most likely to improve the condition or status of variables for which there is already considerable evidence of impact on student learning" [7] (p. 698). With that focus, we briefly outline the following directions for future research on trust framed by the four Paths posited by Leithwood et al. as a "simple and compelling" conceptualization of leadership influences [7] (p. 673):

- The Rational Path is concerned with the core enterprises of schooling, namely elements of curriculum, instruction, assessment, and student learning. Mediating variables such as academic 
press and disciplinary climate have been associated with the Rational Path as possible mediating variables. Trust has been shown to be associated with academic press, which raises the question of how trust might be related to other variables of the instructional enterprise, such as disciplinary climate, the articulation of a share mission and vision for a school, formative and summative assessment practices, or remediation efforts.

- The Emotional Path includes "feelings, dispositions, and affective states" [7] (p. 675), and Leithwood et al. identified collective teacher efficacy and trust as possible associated constructs. Collective teacher efficacy has been shown to be related to trust, but Leithwood et al. found non-significant contribution of trust to student achievement. However, if trust is associated with multiple variables, then is its role in student achievement differential or cumulative among these other variables? Also, how is trust related to other possible factors of the Emotions Path such as those alluded to in the most recently proposed educational leadership standards: sense of safety and emotional well-being of students, teacher perceptions of working conditions, the presence and pervasiveness of positive relationships within the school, and student enjoyment of student learning [18]?

- The Organizational Path concerns structures, policies, and operating practices, for which Leithwood et al. [7] identified instructional time and professional learning communities as associated variables. The relationship between professional learning communities and trust has been shown, but how is trust related to the allotment and protection of instructional time, and how is trust related to other possible organizational variables such as sufficient resources to support instruction, ability grouping practices, class size, as well as the adequacy and maintenance of the physical environment?

- The Family Path potentially includes both alterable and unalterable variables that have to do with student experiences in their domestic lives outside of school, which Leithwood et al. [7] cite as accounting for more than half of the variation in student achievement. Leithwood and his colleagues identified access to supportive adult influences and the presence of a computer in the home as variables. However, characterizing the Family Path in terms of variables identified in educational leadership standards may prove more meaningful, in particular, variables that may be associated with trust such as those articulated in the proposed new Standard 7-Communities of Engagement for Families:

○ Promoting communities of engagement for families and other stakeholders

o Promoting understanding, appreciation, and use of the community's diverse cultural, social, and intellectual resources

o Nurturing a sense of approachability and sustaining positive relationships with families and caregivers

o Building and sustaining productive relationships with community partners in the government, non-profit, and private sectors

o Advocating for policies and resources for the community

o Understanding and engaging with community needs, priorities, and resources [18].

In sum, trust would seem to play a role in each of the four paths delineated by Leithwood and his colleagues [7]. For schools to truly become the vibrant learning communities envisioned by school 
improvement and reform efforts, attention must be paid to issues of trust. An understanding of the conditions and processes that enable teachers and administrators to learn to trust each other and cooperate together is critical as schools are increasingly faced with the volatility of changing expectations. Schools where trust is high can help avoid rigidity and a "hunkering down" mentality that organizations often fall victim to in the midst of crisis [88]. The open communication, commitment, and professionalism that high trust environments make possible confers a strategic advantage to schools in times of change. The candor that trusting relationship fosters can allow for more effective problem solving and can provide an additional bulwark to an organization when confronting turbulent environments and new competitive forces afoot $[16,17,37,39,88,89]$. Thus, the challenge of cultivating high trust school environments may be one of the most important tasks facing school leaders in the times in which we live.

\section{Author Contributions}

Both authors made an equal contribution to this work.

\section{Conflicts of Interest}

The authors declare no conflict of interest.

\section{References}

1. Tschannen-Moran, M.; Gareis, C.R. Faculty trust in the principal: An essential ingredient in high-performing schools. J. Educ. Admin. 2015, 53, 66-92.

2. Bryk, A.S.; Schneider, B. Trust in Schools: A Core Resource for School Improvement; Russell Sage Foundation: New York, NY, USA, 2002.

3. Tschannen-Moran, M. Trust Matters: Leadership for Successful Schools, 2nd ed.; Jossey-Bass: San Francisco, CA, USA, 2014.

4. Uline, C.; Miller, D.; Tschannen-Moran, M. School effectiveness: The underlying dimensions. Educ. Admin. Q. 1998, 34, 462-483.

5. Tschannen-Moran, M.; Hoy, W.K. Trust in schools: A conceptual and empirical analysis. J. Educ. Admin. 1998, 36, 334-352.

6. Council of Chief State School Officers. Educational Leadership Policy Standards: ISLLC 2008; Council of Chief State School Officers: Washington, DC, USA, 2008.

7. Leithwood, K.; Patten, S.; Jantzi, D. Testing a conception of how school leadership influences student learning. Educ. Admin. Q. 2010, 46, 671-706, doi:10.1177/0013161x10377347.

8. Hallinger, P.; Heck, R.H. Reassessing the principal's role in school effectiveness: A review of empirical research, 1980-1995. Educ. Admin. Q. 1996, 32, 5-44.

9. Zeinabadi, H.R. Principal-teacher high-quality exchange indicators and student achievement: Testing a model. J. Educ. Admin. 2014, 52, 404-420.

10. Chugtai, A.A.; Buckley, F. Linking trust in the principal to school outcomes: The mediating role of organizational identification and work engagement. Int. J. Educ. Manag. 2009, 23, 574-589. 
11. Forsyth, P.B.; Adams, C.M. Organizational predictability, the school principal, and achievement. In Trust Relationships and School Life: The Influence of Trust on Learning, Teaching, Leading, and Bridging; Van Maele, D., Forsyth, P.B., Van Houtte, M., Eds.; Springer: New York, NY, USA, 2014.

12. Handford, V.; Leithwood, K. Why teachers trust school leaders. J. Educ. Admin. 2013, 51, 194-212.

13. Notman, R.; Henry, D.A. Building and sustaining successful school leadership in New Zealand. Leader. Pol. Sch. 2011, 10, 375-394, doi:10.1080/15700763.2011.610555.

14. Salfi, N.A. Successful leadership practices of head teachers for school improvement: Some evidence from Pakistan. J. Educ. Admin. 2011, 49, 414-432, doi:10.1108/09578231111146489.

15. Tschannen-Moran, M. Fostering organizational citizenship: Transformational leadership and trust. In Studies in Leading and Organizing Schools; Hoy, W.K., Miskel, C.G., Eds.; Information Age Publishing: Greenwich, CT, USA, 2003; pp. 157-179.

16. Tschannen-Moran, M. Fostering teacher professionalism: The role of professional orientation and trust. Educ. Admin. Q. 2009, 45, 217-247.

17. Tschannen-Moran, M. The interconnectivity of trust in schools. In Trust and School Life: The Role of Trust for Learning, Teaching, Leading, and Bridging; Van Maele, D., Forsyth, P.B., Van Houtte, M., Eds.; Springer: New York, NY, USA, 2014; pp. 57-81.

18. Council of Chief State School Officers. Educational Leadership Policy Standards: ISLLC 2014 Draft for Public Comment; Council of Chief State School Officers: Washington, DC, USA, 2014.

19. Baier, A.C. Moral Prejudices; Harvard University Press: Cambridge, MA, USA, 1994.

20. Bigley, G.A.; Pearce, J.L. Straining for shared meaning in organization science: Problems of trust and distrust. Acad. Manag. Rev. 1998, 23, 405-421.

21. Rousseau, D.; Sitkin, S.B.; Burt, R.; Camerer, C. Not so different after all: A cross-discipline view of trust. Acad. Manag. Rev. 1998, 23, 393-404.

22. Solomon, R.C.; Flores, F. Building Trust in Business, Politics, Relationships, and Life; Oxford University Press: New York, NY, USA, 2001.

23. Zand, D.E. The Leadership Triad: Knowledge, Trust, and Power; Oxford University Press: New York, NY, USA, 1997.

24. Putnam, R.D. Bowling Alone: The Collapse and Revival of American Community; Simon and Schuster: New York, NY, USA, 2000.

25. Cummings, L.L.; Bromily, P. The Organizational Trust Inventory (OTI): Development and Validation. In Trust in Organizations; Kramer, R., Tyler, T., Eds.; Sage: Thousand Oaks, CA, USA, 1996; pp. 302-330.

26. McAllister, D.J. Affect- and cognition-based trust as foundations for interpersonal cooperation in organizations. Acad. Manag. Rev. 1995, 38, 24-59.

27. Butler, J.K., Jr.; Cantrell, R.S. A behavioral decision theory approach to modeling dyadic trust in superiors and subordinates. Psychol. Rep. 1984, 55, 19-28.

28. Bird, J.J.; Chuang, W.; Watson, J.; Murray, L. Teacher and principal perceptions of authentic leadership: Implications for trust, engagement, and intention to return. J. Sch. Leader. 2012, 22, 425-461.

29. Rotter, J.B. A new scale for the measurement of interpersonal trust. J. Pers. 1967, 35, 651-665. 
30. Bird, J.J.; Chuang, W.; Watson, J.; Murray, L. Relationships among principal authentic leadership and teacher trust and engagement levels. J. Sch. Leader. 2009, 19, 153-171.

31. Hoy, W.K.; Henderson, J.E. Principal authenticity, school climate, and trust. Alberta J. Educ. Res. 1983, 29, 123-130.

32. Hoy, W.K.; Kupersmith, W.J. The meaning and measure of faculty trust. Educ. Psychol. Res. 1985, 5, 1-10.

33. Simons, T.L. Behavioral integrity as a critical ingredient for transformational leadership. J. Organ. Change 1999, 12, 89-104.

34. Dasgupta, P. Trust as a commodity. In Trust: Making and Breaking Cooperative Relations; Gambetta, D., Ed.; Basil Blackwell: Cambridge, MA, USA, 1988; pp. 213-238.

35. Sapienza, H.J.; Korsgaarg, M.A. Managing investor relations: The impact of procedural justice in establishing and sustaining investor support. Acad. Manag. J. 1996, 39, 544-574.

36. Kramer, R.M. Divergent realities and convergent disappointments in the hierarchic relation: Trust and the intuitive auditor at work. In Trust in Organizations; Kramer, R., Tyler, T., Eds.; Sage: Thousand Oaks, CA, USA, 1996; pp. 216-245.

37. Mishra, A.K. Organizational responses to crisis: The centrality of trust. In Trust in Organizations; Kramer, R., Tyler, T., Eds.; Sage: Thousand Oaks, CA, USA, 1996; pp. 261-287.

38. Hoy, W.K.; Sweetland, S.R. Bureaucracies that work: Enabling not coercive. J. Sch. Leader. 2000, 10, 525-541.

39. Hoy, W.K.; Sweetland, S.R. Designing better schools: The meaning and nature of enabling school structure. Educ. Admin. Q. 2001, 37, 296-321.

40. Mitchell, R.; Ripley, J.; Adams, C.; Raju, D. Trust: An essential ingredient in collaborative decision making. J. Sch. Publ. Relat. 2011, 32, 145-170.

41. Tschannen-Moran, M. Collaboration and the need for trust. J. Educ. Admin. 2001, 39, 308-331.

42. Hoy, W.K.; Tarter, C.J. Administrators Solving the Problems of Practice: Decision-Making, Concepts, Cases, and Consequences, 3rd ed.; Allyn \& Bacon: Boston, MA, USA, 2008.

43. Moye, M.J.; Henkin, A.B.; Egley, R.J. Teacher-principal relationships: Exploring linkages between empowerment and interpersonal trust. J. Educ. Admin. 2005, 43, 260-277.

44. Short, P.M.; Greer, J.T. Leadership in Empowered Schools: Themes from Innovative Efforts; Merrill: Columbus, OH, USA, 1997.

45. Vescio, V.; Ross, D.; Adams, A. A review of research on the impact of professional learning communities on teaching practice and student learning. Teach. Teach. Educ. 2008, 24, 80-91.

46. Louis, K.S.; Kruse, S. Professionalism and Community: Perspectives on Reforming Urban Schools; Corwin: Thousand Oaks, CA, USA, 1995.

47. Marks, H.M.; Louis, K.S. Does teacher empowerment affect the classroom? The implications of teacher empowerment for instructional practice and student academic performance. Educ. Eval. Pol. Anal. 1997, 19, 245-275.

48. Cloke, K.; Goldsmith, J. The End of Management and the Rise of Organizational Democracy; Jossey-Bass: San Francisco, CA, USA, 2002.

49. Louis, K.S.; Dretzkea, B.; Wahlstrom, K. How does leadership affect student achievement? Results from a national US survey. Sch. Effect. Sch. Improv.: Int. J. Res. Pol. Pract. 2010, 21, 315-336. 
50. Adams, C.M.; Forsyth, P.B. Promoting a culture of parent collaboration and trust: An empirical study. J. Sch. Publ. Relat. 2007, 28, 32-56.

51. Hallinger, P. Instructional leadership and the school principal: A passing fancy that refuses to fade away. Leader. Pol. Sch. 2005, 4, 221-239.

52. Hallinger, P. Leading educational change: Reflections on the practice of instructional and transformational leadership. Camb. J. Educ. 2003, 33, 329-351.

53. Leithwood, K.; Jantzi, D.; Steinbach, R. Changing Leadership for Changing Times; Open University Press: Philadelphia, PA, USA, 1999.

54. Coldren, A.F.; Spillane, J.P. Making connections to teaching practice: The role of boundary practices in instructional leadership. Educ. Pol. 2007, 21, 369-396.

55. Marks, H.M.; Printy, S.M. Principal leadership and school performance: An integration of transformational and instructional leadership. Educ. Admin. Q. 2003, 39, 370-397.

56. Robinson, V.M.J.; Lloyd, C.A.; Rowe, K.J. The impact of leadership on student outcomes: An analysis of the differential effects of leadership types. Educ. Admin. Q. 2008, 44, 635-674, doi:10.1177/0013161X08321509.

57. May, H.; Supovitz, J.A. The scope of principal efforts to improve instruction. Educ. Admin. $Q$. 2011, 47, 332-352, doi:10.1177/0013161X10383411.

58. Blase, J.; Blase, J. Handbook of Instructional Leadership: How Really Good Principals Promote Teaching and Learning; Corwin Press: Thousand Oaks, CA, USA, 1998.

59. Brown, K.M.; Anfara, V.A.; Roney, K. Student achievement in high performing, suburban middle schools and low performing, urban middle schools: Plausible explanations for the differences. Educ. Urban Soc. 2004, 36, 428-456, doi:10.1177/0013124504263339.

60. Finnigan, K.S. Principal leadership and teacher motivation under high-stakes accountability policies. Leader. Pol. Sch. 2010, 9, 161-189, doi:10.1080/15700760903216174.

61. Heck, R.H.; Moriyama, K. Examining relationships among elementary schools' contexts, leadership, instructional practices, and added-year outcomes: A regression discontinuity approach. Sch. Effect. Sch. Improv. 2010, 21, 377-408, doi:10.1080/09243453.2010.500097.

62. Cotton, K. Principals and Student Achievement: What the Research Says; Association for Supervision and Curriculum Development: Alexandria, VA, USA, 2003.

63. Hallinger, P.; Bickman, L.; Davis, K. School context, principal leadership, and student reading achievement. Elem. Sch. J. 1996, 96, 527-549.

64. Leithwood, K.; Louis, K.S.; Anderson, S.; Wahlstrom, K. Review of Research: How Leadership Influences Student Learning; The Wallace Foundation: New York, NY, USA, 2004.

65. Supovitz, J.A.; Sirinides, P.; May, H. How principals and peers influence teaching and learning. Educ. Admin. Q. 2010, 46, 31-56, doi:10.1177/1094670509353043.

66. Murphy, J.F.; Weil, M.; Hallinger, P.; Mitman, A. Academic press: Translating high expectations into school practices and classroom practices. Educ. Leader. 1982, 40, 22-26.

67. Goddard, R.D.; Sweetland, S.R.; Hoy, W.K. Academic emphasis of urban elementary schools and student achievement in reading and mathematics: A multilevel analysis. Educ. Admin. Q. 2000, 36, 683-702, doi:10.1177/00131610021969164.

68. Hoy, W.K.; Hannum, J.W. Middle school climate: An empirical assessment of organizational health and student achievement. Educ. Admin. Q. 1997, 33, 290-311. 
69. Hoy, W.K.; Hannum, J.W.; Tschannen-Moran, M. Organizational climate and student achievement: A parsimonious and longitudinal view. J. Sch. Leader. 1998, 8, 336-359.

70. Bryk, A.S.; Lee, V.E.; Holland, P.B. Catholic Schools and the Common Good; Harvard University Press: Cambridge, MA, USA, 1993.

71. Hoy, W.K.; Tarter, C.J. The Road to Open and Healthy Schools: A Handbook of Change; Sage: Thousand Oaks, CA, USA, 1997.

72. Hoy, W.K.; Tarter, C.J.; Bliss, J.R. Organizational climate, school health, and effectiveness: A comparative analysis. Educ. Admin. Q. 1990, 26, 260-279.

73. Hoy, W.K.; Tarter, C.J.; Kottkamp, R.B. Open Schools/Healthy Schools; Sage: Beverly Hills, CA, USA, 1991.

74. Alig-Mielcarek, J.; Hoy, W.K. Instructional leadership. In Educational Leadership and Reform; Hoy, W.K., Miskel, C.G., Eds.; Information Age Publishers: Greenwich, CT, USA, 2005.

75. Ylimaki, R.M., Ed. The New Instructional Leadership: ISLLC Standard Two; Routledge/UCEA: New York, NY, USA, 2014.

76. Mitchell, R.M.; Kensler, L.A.; Tschannen-Moran, M. Examining the effects of instructional leadership on school academic press and school achievement. J. Sch. Leader. 2015, 25, 223-251.

77. Bandura, A. Perceived self-efficacy in cognitive development and functioning. Educ. Psychol. 1993, 28, 117-148.

78. Bandura, A. Self-Efficacy: The Exercise of Control; Freeman: New York, NY, USA, 1997.

79. Tschannen-Moran, M.; Salloum, S.J.; Goddard, R.D. Context matters: The Influence of Collective Beliefs and Norms. In International Handbook of Research on Teachers' Beliefs; Fives, H., Gill, M.G., Eds.; Routledge: New York, NY, USA, 2014.

80. Goddard, R.D.; Tschannen-Moran, M.; Hoy, W.K. A multilevel examination of the distribution and effects of teacher trust in students and parents in urban elementary schools. Elem. Sch. J. 2001, 102, 3-17.

81. Tschannen-Moran, M.; Barr, M. Fostering student achievement: The relationship between collective teacher efficacy and student achievement. Leader. Pol. Sch. 2004, 2, 187-207.

82. Tschannen-Moran, M.; Goddard, R.D. Collective Efficacy and Trust: A Multilevel Analysis. In Proceedings of the Annual Meeting of the American Educational Research Association, Seattle, WA, USA, 11 April 2001.

83. Seashore, K.; Kruse, S.D. Professionalism and Community: Perspectives on Reforming Urban Schools; Broad Street Books: Branchville, NJ, USA, 1995.

84. Putnam, R.T.; Borko, H. Teacher Learning: Implications of New Views of Cognition. In The International Handbook of Teachers and Teaching; Biddle, B.J., Good, T.L., Goodson, I.F., Eds.; Kluwer: Dordrecht, The Netherlands, 1997; pp. 1223-1296.

85. Cranston, J. Relational trust: The glue that binds a professional learning community. Alberta J. Educ. Res. 2011, 57, 59-72.

86. Wahlstrom, K.L.; Louis, K.S. How teachers experience principal leadership: The roles of professional community, trust, efficacy, and shared responsibility. Educ. Admin. Q. 2008, 44, $458-495$. 
87. Whitener, E.M.; Brodt, S.E.; Korsgaard, M.A.; Werner, J.M. Managers as initiators of trust: An exchange relationship framework for understanding managerial trustworthy behavior. Acad. Manag. Rev. 1998, 23, 513-530.

88. Daly, A. Rigid response in an age of accountability: The potential of leadership and trust. Educ. Admin. Q. 2009, 45, 168-216.

89. Tschannen-Moran, M.; Hoy, W.K. A multidisciplinary analysis of the nature, meaning, and measurement of trust. Rev. Educ. Res. 2000, 71, 547-593.

(C) 2015 by the authors; licensee MDPI, Basel, Switzerland. This article is an open access article distributed under the terms and conditions of the Creative Commons Attribution license (http://creativecommons.org/licenses/by/4.0/). 